\title{
El Derecho Procesal Constitucional como fenómeno histórico social y como ciencia
}

Eduardo Ferrer Mcgregor

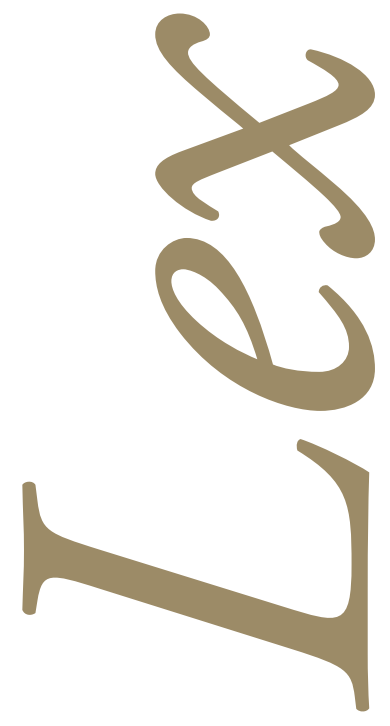




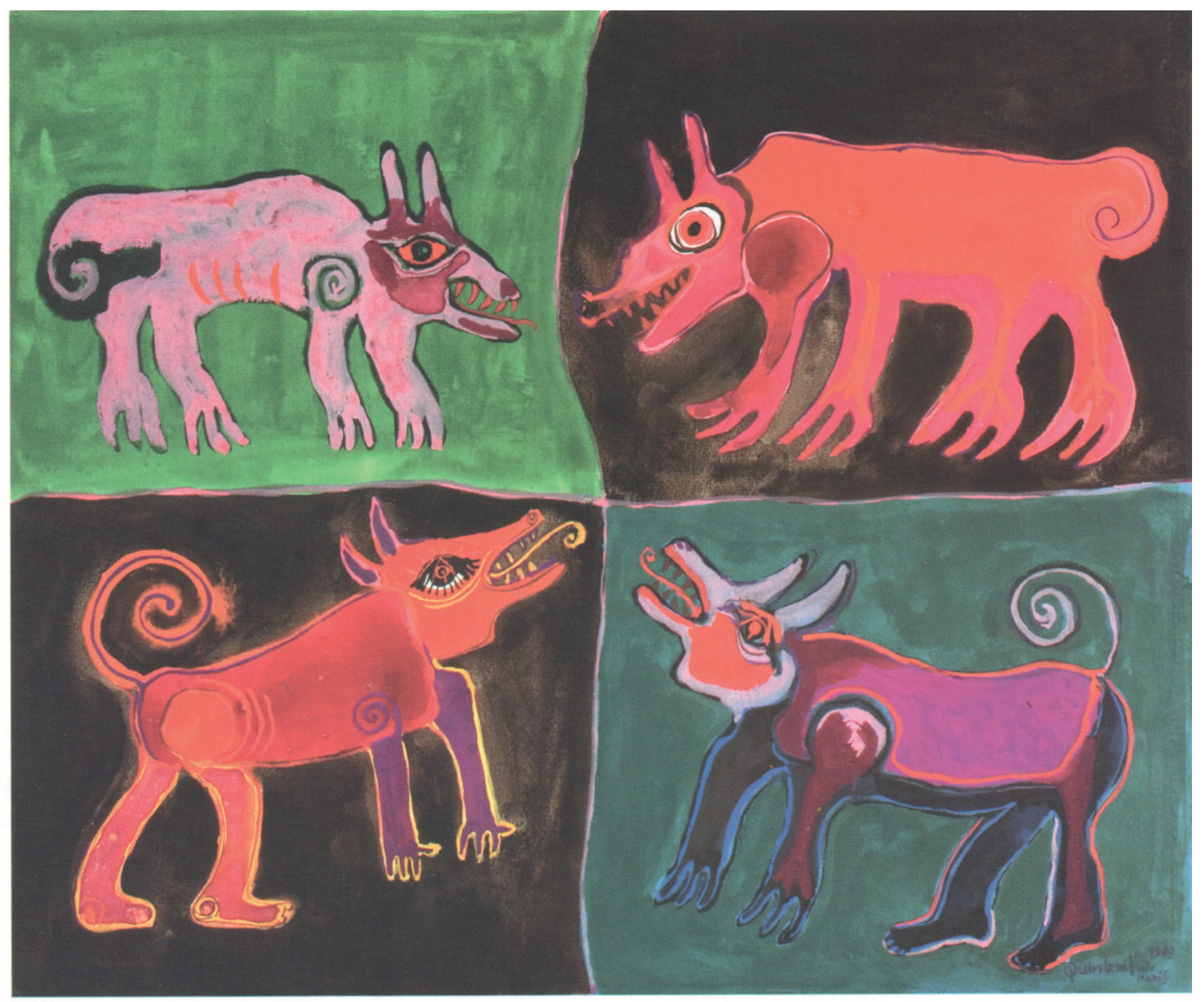

Filigrana entre los perros. Técnica mixta, $1962(38 \mathrm{~cm}$. x $45.5 \mathrm{~cm}$.) 


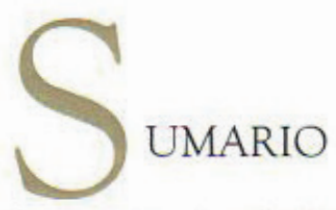

I. La ciencia procesal y la ciencia constitucional. II. El derecho procesal constitucional como fenómeno histórico social. III. El derecho procesal constitucional como ciencia. Cuatro etapas de desarrollo: A) precursora (1928-42), B) descubrimiento procesal (1944-47), C) desarrollo dogmático procesal (1946-55) y D) definición conceptual y sistemática

\section{LA CIENCIA PROCESAL Y LA CIENCIA CONSTITUCIONAL}

La ciencia del derecho es una sola. Tradicionalmente se ha dividido en dos grandes ramas: derecho público y derecho privado. Así ha prevalecido desde Roma, no sin cierta polémica, en el que la división entre el ius privatum y el ius publicum ha dominado a partir de la fórmula de Ulpiano: publicum ius est, quod ad statum rei romanae spectar; privatum quod ad singulorum utilita. rem pertinet (Derecho público es el que afecta a la utilidad del Estado; Derecho privado el que se refiere a la utilidad de los particulares). A partir de esta concepción, han surgido teorias y criterios para tratar de distinguir estas grandes ramas juridicas, atendiendo a los aspectos materiales (contenido de intereses tutelados), formales (norma externa de las relaciones juridicas) subjetivos (sujetos dotados de imperio), entre otros.'

No es el momento para advertir detenidamente esta evolución y la manera en que han aparecido nuevos enfoques y tendencias, al surgir un tertium genus, como el derecho social, hasta quienes niegan la utilidad de esas distinciones. Por lo que aquí interesa, debemos señalar que es corriente mayoritaria la aceptación relativa a que el derecho procesal y el derecho constitucional

1 Para una aproximación a esta distinción, véase la voz "Derecho público y derecho privado", en Bono, Ricardo N., Enciclopedia juridica Omeba, Tomo VIII. Buenos Aires: Driskill, 1979, pp. 166-171. Asimismo, la voz "Derecho público", en el Diccionario de derecho público (administrativo, constitucional y fiscal), de Emilio FERNANDEZ VÁzQUEZ, Buenos Aires: Astrea, 1981, pp. 217-218. 
forman parte del derecho público y su autonomía científica inicia bajo el perfil del derecho público alemán en la segunda mitad del siglo XIX y se consolidan en el siglo XX.

A) El derecho procesal como parte de la ciencia jurídica, es decir, la moderna ciencia procesal como disciplina autónoma, tiene su origen a partir de la doctrina de los pandectistas alemanes a mediados del siglo XIX. Se afirma por la mejor doctrina procesal que para lograr su autonomia científica influyeron dos acontecimientos. Por una parte, la famosa polémica entre Windscheid y Muther (1856-1857), ${ }^{2}$ al confrontar la primitiva actio romana con la klage germánica, lo que provocó la concepción de la acción como derecho subjetivo diferenciado del derecho material. Como lo expresara Couture, "la separación del derecho y de la acción constituyó un fenómeno análogo a lo que representó para la física la división del átomo", siendo a partir de ese momento "que el derecho procesal adquirió personalidad y se desprendió del viejo tronco del derecho civil". ${ }^{3}$ Por la otra, se ha estimado fundamental la aparición de la obra de Oskar von Bülow (1868) sobre la Teoría de las excepciones procesales y de los presupuestos procesales, ${ }^{4}$ al marcar el inicio del derecho procesal como ciencia. ${ }^{5}$ A decir de Alcalá-Zamora y Castillo, la obra de Bülow vendría a significar para el derecho procesal lo que Beccaria para el derecho penal. ${ }^{6}$ Esta obra marca el inicio de un desarrollo dogmático nuevo, por dos razones fundamentales: primero, por haber encauzado la naturaleza del proceso en una corriente publicista, cuyas interpretaciones privatistas (contrato o cuasicontrato) quedaron arrumbadas; y segundo, por haber provocado todo un movimiento científico de gran calado, primero en Italia y seguida con renovación en el mundo. ${ }^{7}$ Büllow estudia al proceso como una relación juridica, postura que fue seguida por Kohler en su obra El proceso como relación jurídica (1988). En esos años se va consolidando la nueva concepción del derecho procesal, seguida con autores como Stein, Degenkolb y la trascendental obra de Adolf Wach, La pretensión de declaración: un aporte a la teoria de la pretensión de protección del derecho. ${ }^{8}$

2 Respecto de esta polémica: Polemica intomo ali actio: Windscheid-Muther, traducción del alemán de Ernst Heinistz y Giovanni Publiese, Florencia: Sansón, 1954. Sobre las posturas de la polémica Windscheid-Muther, así como las corrientes contemporáneas sobre la acción procesal, véase FERrer MAC-GrEGor, Eduardo, "Sobre la naturaleza juridica de la acción”, en Cuadernos Procesales. Organo de divulgación del Colegio de Profesores de Derecho Procesal de la Facultad de Derecho de la UNAM, A.C., México: Ciudad Universitaria, año III, julio de 1999, núm. 5, pp. 1.9 .

3 Couture, Eduardo J., Fundamentos de derecho procesal civil, op. cit., pp. 63-64

4 Trad. de Miguel Ángel Rosas Lichtschein, Buenos Aires: EJEA, 1964. La obra original: Die Lehre von den Proces seinreden und die Processeoraussetzungen, publicado por Emil roth en Giesen, 1868.

5 Goldschmid, James, Teoria general del proceso, trad. de Leonardo Prieto Castro, Barcelona: Labor, 1936, p. 15; Chiovenda, Giuseppe, Principios de derecho procesal civil, trad. de José Casais y Santaló, Madrid: Reus, 1922, tomo I, p. 83.

- Cfr., "Evolución de la doctrina procesal", en su obra Estudios de teoria general e historia del proceso (1945-1972), México: UNAM, Tomo II, núms. 12-13, 1992, p. 293.

7 Cfr. lbidem, p. 308.

8 Trad. de Juan M. Semon, Buenos Aires: EjEA, 1962. 
A partir de entonces y especialmente con el desarrollo posterior del procesalismo científico italiano a principios del siglo XX encabezado por Giuseppe Chiovenda, en su famosa prolusión leida en la Universidad de Bolonia en $1903,{ }^{9}$ la ciencia del derecho procesal adquiere su florecimiento, alcanzando su consagración durante la primera mitad del mismo siglo. Discípulos y condiscípulos continuaron el desarrollo de la dogmática procesal, como Francesco Carnelutti, Piero Calamandrei, Enrico Redentti, Enrico Tulio Liebman, Salvatore Satta, Enrico Allorio, Ugo Rocco, Vicenzo Manzini, Emilio Betti, Marco Tulio Zanzuchi, Vittorio Denti, Virgilio Andrioli, Eugenio Florian, Mauro Cappelletti, solo por mencionar a juristas italianos de gran calado intelectual, sin menoscabo del desarrollo en Alemania (Wach, Kohler, Hellwig, Schönke, Stein, Kisch, Rosenberg, Goldschmidt, etc.) y posteriormente en España (Francisco Beceña, Leonardo Prieto-Castro, Jaime Guasp, Manuel de la Plaza, Emilio Gómez Orbaneja y Miguel Fenech, entre otros).

En Latinoamérica la corriente cientifica del proceso se conoció y desarrolló por juristas exiliados, de la talla de Rafael de Pina Milán y especialmente Niceto Alcalá-Zamora y Castillo (en México), Santiago Sentís Melendo y Marcello Finzi (en Argentina), Enrico Tulio Liebman (en Brasil) y James Goldschmith (en Uruguay). Entre las figuras latinoamericanas que coadyuvaron notablemente al desarrollo cientifico procesal, se encuentran Eduardo Juan Couture (Uruguay), Ramiro Podetti, Hugo Alsina, Eduardo B. Carlos, Jorge A. Clariá Olmedo (Argentina) y Alfredo Buzaid (Brasil), entre otros.

Así, el fenómeno histórico social o, si se prefiere, el hecho histórico "de lo procesal" o "procedimental" existió desde la antigüedad. En cambio el estudio cientifico de dicho fenómeno ocurrió a partir de su autonomía con las áreas sustantivas. Esto no significa que no deban estudiarse dichos antecedentes, sino más bien se quiere hacer énfasis en que el derecho procesal nace, como ciencia, a partir de la segunda mitad del siglo XIX y no con los procesos y procedimientos, o las magistraturas o jurisdicciones que los resolvian instituidas desde la antigüedad. Alcalá-Zamora y Castillo de manera gráfica lo expone diciendo "el proceso como realidad es muy anterior al proceso como literatura"10 y así realiza una clasificación de las cinco etapas de la evolución del pensamiento procesal, desde el periodo primitivo, etapa judicialista, escuela practicista, periodo del procedimentalismo, hasta la fase actual de evolución en la que nos encontramos denominada procesalismo cientifico. ${ }^{11}$

9La acción en el sistema de los derechos, trad. de Santiago Sentis Melendo, Valparaiso, Edeval, 1922 (L'azione nel sistema dei diritti, Bolonia, 1903).

10 "Evolución de la doctrina procesal", op. cit., p. 308.

1 Cfr. op. ùlt. cit., pp. 293.325. Esta clasificación ha sido ampliamente acogida. La utilizan, entre otros, GOMEZ Lara, Cipriano, Teoria general del proceso, 10 ed., México: Oxford, 2004, pp. 67-78; José Ovalle Favela, José, Teoria general del proceso, 6 ed., México: Oxford, pp. 43-35; Briseño Sierra, Humberto, Derecho procesal, $2^{2}$ ed., Harla, 1995, p. 306. Véanse los textos más contemporáneos de Armienta Calderon, Gonzalo, Teoria general del 
Este movimiento cientifico, que iniciara bajo la concepción del derecho público alemán de la segunda mitad del siglo XIX (especialmente con Windscheid, Muther, Büllow, Kohler y Wach), y se forjara a principios del siglo XX en Italia a partir de Giuseppe Chiovenda (1872. 1937) y desarrollada por su escuela: Carnellutti, Calamandrei, Liebmann, etc., condujo en la segunda mitad de dicho siglo a la adopción de una teoria general del proceso (fervientemente defendida por Carnellutti) o, como lo prefiere denominar Alcalá-Zamora y Castillo, de una teoria general del derecho procesal, concebida como la exposición de los conceptos, instituciones y principios comunes a las distintas ramas del enjuiciamiento, que incluso se adoptó como asignatura universitaria. ${ }^{12}$

Como puede apreciarse, si bien es cierto que se suele considerar la obra de Bülow (1868) como el inicio de la moderna ciencia procesal, lo cierto es que la construcción cientifica es un eslabón en el pensamiento al ir construyendo, con base en los predecesores e influjos sociales, politicos y jurídicos del momento, nuevas concepciones y teorias. El propio Alcalá-Zamora que ha estudiado como pocos la evolución de la doctrina procesal, reconoce que las etapas culturales no son compartimientos estancos sino momentos capitales enlazados entre si, de tal suerte que antes de Bülow hay un Wetzell, existe una polémica Windscheid-Muther y áun antes en pleno siglo XVII se encuentra un Benedicto Carpzov. ${ }^{13}$ Incluso, sin desconocer el mérito de Bülow, señala Alcalá que en realidad su teoría constituye un desenvolvimiento de las ideas de Hegel, que la vislumbra y de Hollweg que la sustenta. Incluso, la obra de Bülow no fue de exposición sistemática, como si lo fue la de Wach (1885). ${ }^{14} \mathrm{Y}$ concatenando eslabones "La influencia de Wach y de Klein sobre Chiovenda"15 resultan claros, por lo que en realidad el padre del procesalismo científico italiano tuvo un influjo directo de la corriente cientifica de Alemania y Austria.

B) Algo similar también puede advertirse en el estudio científico del derecho cònstitucional, cuyo inicio se remonta con la adopción de las Constituciones escritas a finales del siglo XVIII. Se ha considerado que es en esa época donde inician, con poca vigencia, las primeras cátedras de diritto costituzionale en Ferrara (1797), en Pavia (1797) y Bolonia (1798), y donde aparece una

proceso (principios, instituciones y categorias procesales), México: Porrúa, 2003, pp. 25.29; SAid, Alberto, y GonzALEz Gutierrez, Isidro M., Teoría general del proceso, México: Iure Editores, 2006, pp. 84-116.

12 Cfr. Alcala-Zamora y Castillo, Niceto, "La teoria general del proceso y la enseñanza del derecho procesal", en Revista lberoamericana de derecho procesal, núm. 1, 1968, pp. 9-91.

13 Cfr, "Evolución de la doctrina procesal", op. cit., p. 293.

14 Handbuch des Deutschen Civilprozessrechts, tomo I, Leipzig, 1885; citada por Alcalá Zamora y Castillo, op. últ. cit, p. 308 .

15 Asi se titula un detallado estudio de Niceto Alcalá-Zamora y Castillo, publicado en sus Estudios de teoria general e historia del proceso (1945-1972), op. cit., tomo II, núms. 12-13, pp. 547-570. Publicado originalmente en Revista de Derecho Procesal, Buenos Aires, 1947, I, pp. 389.410 (en homenaje a Chiovenda en su décimo aniversario de su muerte). 
primera obra sobre la materia en la Universidad de Ferrara, por el profesor Giuseppe Compagnoni di Luzo, que escribiera su Elementi di diritto costituzionale democrático ossia Principii di giuspubblico universale (Venecia, 1797); ${ }^{16}$ si bien con anterioridad en la Universidad de Oxford, el profesor William Blackstone (1758) enseñaba la constitución y las leyes de Inglaterra (sin denominarla derecho constitucional), lo que lo llevó a escribir sus influyentes Commentaries on the Laws of England (1765). ${ }^{17}$

Durante el siglo XIX se fueron creando paulatinamente cátedras de derecho constitucional. En España, debido a la breve vigencia de la Constitución de Cádiz de 1812, en cuyo artículo 368 establecia la obligación de que se explicase la constitución "en todas las Universidades y establecimientos literarios donde se enseñen las ciencias eclesiásticas y políticas", surge la primera cátedra en Valencia, el 21 de septiembre de 1813, cuyo titular fue el civilista Nicolás Garely; y se inaugura en Madrid el 2 de febrero de 1814, con Miguel Garcia de la Madrid. En Francia, primero con la denominación de droit publique o droit politique (1791) y luego con el rótulo de droit constitutionnel (1834) en la Sorbona, París, a iniciativa de Guizot y cuyo primer catedrático fue el italiano Pellegrino Rossi (que había estudiado en Bolonia donde ya se enseñaba), expresión aceptada por la Academia Francesa en 1835. Si bien en algunos casos combinado con la ciencia política. Más tarde en España el derecho constitucional se incluye en los planes de estudio en 1835, inicialmente con la denominación de derecho público y a partir de 1857 con la expresión "derecho político" o "derecho político constitucional" ${ }^{18}$ Con la consagración de las constituciones escritas en el siglo XX se fue acentuando la enseñanza como disciplina autónoma y especialmente al consolidarse la corriente cientifica del derecho constitucional.

Con independencia de las cátedras, se suele considerar el surguimiento de la disciplina constitucional con carácter autónomo, a partir del moderno derecho público alemán bajo una óptica estricta del método jurídico. Especialmente se señala la obra de Karl Friedrich Von

16 Cfr. Lucas Verdú, Pablo, "Paolo di Ruffía y la ciencia italiana del derecho constitucional", en BisCARETTI DI RufflA, Paolo, Derecho constitucional, 3a ed., Madrid: Tecnos, 1987, pp. 21-53, en p. 21.

17 Cfr. Linares Quintana, Segundo V., Tratado de la ciencia del derecho constitucional, 2 ed., Buenos Aires, Plus Ul. tra, 1977, Tomo II, pp. 41-45. La obra completa consta de XI tomos. Linares se apoya para estas afirmaciones en las obras de Jorge Aja Espil, En los origenes de la tradística constitucional, Buenos Aires: Abeledo Perrot, 1968, pp. 49 y ss.; y de Massimo Palmerini, Introduzione allo studio del diritto costituzionale, Edizione dell'Ateneo, 1947, p. 2. En el mismo sentido SAGÜEs, Néstor P., Elementos de derecho constitucional, 2a reimpresión de la $3^{\text {a }}$ ed., Buenos Aires: Astrea, 2003, tomo I, pp. 42.43.

18 Op. últ. cit., pp. 42-44, especialmente Linares Quintana se apoya en Luis Sánchez Agesta, "Las primeras cátedras españolas de derecho constitucional”, en Revista de Estudios Politicos, Madrid, noviembre-diciembre de 1962, núm. 126, p. 157; Rubio Llorente, Francisco, voz "Derecho constitucional”, en Enciclopedia juridica civitas, vol. II, p. 2208; Fernández VAzquez, Emilio, voz "Derecho constitucional", en Diccionario de derecho priblico (administrativo, constitucional y fiscal), op. cit., pp. 204-209. Asimismo, véase. LucAs Verdú, Pablo, "Paolo di Ruffia y la ciencia italiana del derecho constitucional", op. cit., p. 22. 
Gerber, Grundzùge eines Systems des deutschen Staatsrechts (1865) ${ }^{19}$ (Fundamentos de un sistema del derecho político alemán), que de algún modo puede equipararse a la obra señalada de Bülow para el derecho procesal, no por construir propiamente la autonomía de la disciplina, sino esencialmente por la nueva concepción y repercusión derivada de la misma, es decir, por su concepción y metodologia estrictamente juridica, que con el tiempo desembocó en la ciencia del derecho constitucional.

Como lo señala Garcia-Pelayo, "La aparición del derecho constitucional en el pasado siglo (XIX) no es más que un caso particular de la dispersión del viejo Corpus Iuris Publicii en varias ramas (derecho constitucional, derecho administrativo, derecho penal, derecho procesal), dispersión debido a dos clases de motivos: por un lado, al progreso en la racionalización de los órdenes juridicos y políticos, que da lugar a una serie de separaciones objetivas de tales órdenes (entre justicia y administración, entre éstas y legislación, entre ley y constitución, etc.), con lo que dentro de la realidad juridico-pública surgen unos objetos autónomos que requieren tratamiento autónomo; por otro lado, al progreso en la precisión de los métodos jurídicos que proporcionó el instrumento gnoseológico adecuado para satisfacer las necesidades teóricas y técnicas. En resumen: si bien el nacimiento del derecho constitucional se vincula de un modo inmediato con la problemática planteada por el Estado democrático liberal, responde, sin embargo, a causas más generales y profundas, y de las que ese mismo Estado era efecto". ${ }^{20}$

En esta corriente de la pureza del método juridico, surgen figuras notables como Paul Laband y especialmente Georg Jellinek, que con su Teoria general del estado (1900), se ha considerado como "un hito de profundo significado en el proceso evolutivo, no solamente del derecho constitucional, sino de toda la ciencia jurídica en general". ${ }^{21}$ La utilización del método juridico como técnica de estudio del derecho público, fue seguida en Italia por Vittorio Émmanuele Orlando a partir de la prelusión pronunciada en la Universidad de Palermo, sobre Los criterios técnicos para la reconstrucción del derecho público (1885), ${ }^{22}$ aportación que fue aclarada y complementada por otra obra aparecida en $1952,{ }^{23}$ por lo que es considerado como el padre del derecho público italiano (especialmente del constitucional). Como lo señala Lucas Verdú de la pri-

Cfr., entre otros, Biscaretti di Ruffí, Paolo, Derecho constitucional, 3a. ed., trad. de Pablo Lucas Verdú, Madrid: Tecnos, 1987, p. 74; Linares Quintana, Segundo V., Tratado de la ciencia del derecho constitucional, Tomo II, p. 48.

20 Garcia-Pelayo, Manuel, "Prólogo a la primera edición", Derecho constitucional comparado, Madrid: Alianza Editores, 1999, pp. 9-10. La primera edición es de 1951.

21 Linares Quintana, Segundo V., Tratado de la ciencia del derecho constitucional, Tomo II, p. 55.

22 Cfr. su obra I criteri tecnici per la ricostruzione del diritto pubblico, Módena, 1925. Citada por Lucas Verdu, Pablo, "Paolo di Ruffía y la ciencia italiana del derecho constitucional", op. cit., p. 27.

25 Cfr., su trabajo "La rivoluzione mondiale e il diritto", en Studi di diritto constituzionale en memoria di Luigi Rossi, Giuffrè, Milán, 1952, pp. 729-730. Citado por LuCAs Verdú, Pablo, op. últ. cit., p. 27; notas 22 y 23. 
mera obra señalada de Orlando, "supone una exposición a su programa científico con matices de vibrante manifiesto que anuncia la formación de la dirección técnico-juridica hoy enraizada en Italia" y completa comentando que "era menester una ciencia del derecho concebida como materia y como técnica, en términos juridicos. Lo cual parecería demasiado obvio, pero implicaba la depuración de los ingredientes políticos, filosóficos y sociológicos que dificultaban una ciencia del derecho público sistemático". ${ }^{24}$

En ese sendero de la técnica y dogmática jurídica que se iniciara bajo el empuje del derecho público alemán con Gerber, Laband y Jellinek, progresivamente a finales del siglo XIX y primeras décadas del siglo XX fueron apareciendo autores que le dan sustento a la disciplina jurídico constitucional. El punto de inflexión histórica del cambio, como ha señalado Lombardi, lo representa Vittorio Emmanuele Orlando. Señala este autor que "en su trabajo de 8 de enero de 1889, y que como preludio a sus Cursos de derecho administrativo y constitucional fue leído en la Universidad de Palermo, hace ya casi un siglo, con el título Los criterios técnicos para la reconstrucción juridica del Derecho público, sigue las pautas establecidas en otros estudios anteriores, que fueron también preludios a los Cursos de Módena ( 4 de diciembre de 1885, titulado Orden juridico y orden politico) y Messina (12 de diciembre de 1886, que significativamente se refiere a $L a$ necesidad de una reconstrucción jurídica del Derecho constitucional). En todos ellos se afirma rotundamente la distinción entre el Derecho constitucional y lo que más adelante se llamará "Ciencia de la política", a la vez que se reivindica la autonomía del Derecho constitucional a través de la afirmación de la primacía del momento juridico como objeto y razón de su estudio, con la consiguiente proclamación para el mismo del método propio de las otras ramas de la jurisprudencia como único medio válido para la reconstrucción de sus institutos". ${ }^{25}$ Esta lucha por el método juridico se aprecia con claridad en sus Principi di diritto costituzionale. ${ }^{26}$

Siguiendo la linea iniciada por Orlando, ${ }^{27}$ su más destacado discipulo Santi Romano continuó consolidando el método juridico en el estudio del derecho constitucional. Maestro y discípulo, ambos académicos y politicos, contribuyeron a la consagración del estudio técnico juridico del derecho constitucional. Como señala Lucas Verdú, "Orlando fue el fundador de la moderna escuela italiana del derecho público. Romano significa su definitiva continuación y consolidación". ${ }^{28}$ Santi Romano tuvo una influencia importante como catedrático de derecho constitucional (Universidades de Módena, Pisa, Milán y Roma) y derecho administrativo (Uni-

24 Lucas Verdú, Pablo, "Paolo di Ruffla y la ciencia italiana del derecho constitucional", op. cit. p. 27.

25 Lombard, Giorgio, "Derecho constitucional y ciencia politica en Italia", en Revista de Estudios Politicos; Madrid: Nueva Ėpoca, núm. 22, julio-agosto, 1981, pp. 79-97, en p. 84.

26 Florencia, G. Barbera, 1889.

27 Una recopilación de los estudios de Orlando aparece en su Diritto pubblico generale. Scritti varii (1881-1949) coordinati in sistema, Milán, Dott. A. Giuffrè, 1940.

28 "Paolo di Ruffia y la ciencia italiana del derecho constitucional", op. cit. p. 32. 
versidad de Camerino). Fue miembro del Senado y presidente del Consejo de Estado. Sus obras relativas a L'ordinamento giuridico (1918) y Corso di diritto costituzionale (1926) resultan fundamentales para el desarrollo posterior de la disciplina, hasta llegar a sus Principi di diritto costituzionale (1945) y Frammenti di un dizionario giuridico (1947). ${ }^{29}$

La consolidación de la ciencia del derecho constitucional se fue construyendo significativamente especialmente en Italia, Francia y Alemania. Destacan dentro de la escuela italiana, además de los mencionados Orlando y Santi Romano, Constantino Mortati, Vezio Crisafulli, Egidio Tosato, Leopoldo Elia, Carlo Esposito, Livio Paladin, Mario Galizia, Carlo Lavagna, Paolo Barile, Giorgio Balladore Pallieri, Temistocle Martines, Paolo Biscaretti di Ruffia, Franco Pierandrei, Alessandro Pizzorusso, Alessandro Pace, Antonio La Pérgola, Gustavo Zagrebelsky, Giuseppe de Vergotinni, Franco Modugno, Sergio Bartole y Antonio Ruggeri. ${ }^{30}$

En cuanto a los autores franceses figuran Adhémar Esmein, Eduard Lambert, León Duguit, Boris Mirkine Guetzévitch, ${ }^{31}$ Joseph Barthélemy, Maurice y André Hauriou, Raymond Carré de Malberg, Maurice Duverger, Georges Vedel, Georges Burdeau, Marcel Prélot, Louis Favoreu, Gérard Conac y Michel Troper. ${ }^{32}$

Y en la escuela alemana Hermann Héller, Carl Schmitt, Hans Kelsen, Karl Loewenstein, Rudolf Smend, Konrad Hesse, Theodor Maunz, HeinrichTriepel, Gerhard Leibholz, Ernest Forsthoff, Ernst-Wolfgang Böckenförde, Friedrich Müller y Peter Häberle. Solo por mencionar algunos autores emblemáticos y sin ningún ánimo de exhaustividad, que de manera magistral han sentado las bases de la teoría constitucional y teoría del estado desde una perspectiva juridica, contribuyendo a la consolidación de la ciencia del derecho constitucional. En la actualidad son abundantes los manuales y libros que llevan el titulo de la disciplina, si bien su contenido abarca múltiples capitulos que reflejan su incesante crecimiento: derechos fundamentales, de-

29 Para una valoración general de la obra de Santi Romano, véase Frosint, 'Vittorio, "Las transformaciones de la doctrina del estado en Italia”, en Revista de Estudios Políticos, Madrid, núm. 202, julio-agosto, 1975, pp. 145-154, especialmente pp. 147 y ss.

30 Hay autores que desde la filosofia del derecho, ciencia politica, teoría general del derecho o historia constitucional, han realizado contribuciones especialmente importantes para el derecho constitucional, como Massimo Severo Giannini, Norberto Bobbio, Luigi Ferrajoli, Maurizio Fioravanti y Michelangelo Bovero, entre otros.

31. Si bien este autor enseñó en Petrogrado, se trasladó a Francia después de la primera guerra mundial, obteniendo la nacionalidad francesa y destacando por sus obras juridicas, como lo advierte Linares Quintana, op. cit., p. 132.

32 Sólo se mencionan algunos autores clásicos, si bien existen otros importantes constitucionalistas contemporáneos, como Frank Moderne, Pierre Bon, François Luchaire, Michel Fromont y Dominique Rousseau, entre otros. En general, sobre un sector de la escuela francesa, véase el trabajo de LuCAs Verdú, Pablo, "Maurice Duverger y la nueva escuela francesa de derecho constitucional”, en Boletin de la Universidad Compostelana, Santiago de Compostela, 1959, núm. 67, pp. 283-293. 
rechos humanos, derecho parlamentario, derecho electoral, derecho judicial, derecho regional o estadual, etc. Sagüés advierte la manera en que el derecho constitucional de nuestros dias afronta una verdadera "crisis de crecimiento" debido a su incontenible desarrollo que bien puede causar su fraccionamiento en varias subasignaturas constitucionalistas. ${ }^{33}$

En el ámbito anglosajón también se fue construyendo la ciencia del derecho constitucional, si bien con una construcción pragmática, privilegiando el aspecto técnico y jurisprudencial sobre el dogmático. Solo como una muestra y tampoco con ningún fin de exhaustividad que rebasaria los fines del presente epígrafe, destacan las siguientes obras clásicas referidas al constitucionalismo británico y estadounidense. Entre las primeras: The Reports of Sir Edward Coke (13 partes, 1600-15) e Institutes of the Laws of England (IV vols., 1628-44), de Sir Edward Coke; The Elements of the Common Lawes of England, de Sir Francis Bacon (1630); Commentaries of the Laws of England, de William Blackstone (IV vols. 1765-69); The English Constitution, de Walter Bagehot (1867); La Constitution d'Angleterre, de Jean Louis De Lolme (1771); An introduction to the principles of morals and legislation, de Jeremy Bentham (1789); Reflections on the Revolution of France, de Edmund Burke (1790); Lectures Introductory to the Study of the Law of the Constitution, de Albert Venn Dicey (1885); The American Commonwealth, de James Bryce (1888); The Expansion of the Common Law, de Sir Frederick Pollock (1904); The Constitutional History of England: a Course of Lectures, Maitland, Frederic William (1908); y Studies in the Problem of Sovereignty, de Harold J. Laski (1917); Fundamental Law in English Constitutional History, de J. W. Goug (1958). En la actualidad son abundantes los textos y manuales especialmente con el titulo de Constitutional and Administrative Law. ${ }^{34}$

En cuanto a las segundas: The Federalist, de Alexander Hamilton, James Madison y John Jay (1787-88); The Rights of Man, de Thomas Paine (1791-92); Commentaries on the American Law, de James Kent (IV vols., 1826-30); Commentaries on the Constitution of the United States (III vols, 1833) y Commentaries on the Conflict of Laws (1834), de Joseph Story; De la démocratie en Amérique, de Alexis de Tocqueville (IV vols., 1835-40); La Histoire des États Unis, de Édouard Laboulaye (III vols., 1855-66); The Constitution of the United States: Defined and Carefully Annotated, de George W. Paschal (1868); An Introduction to the Constitutional Law of the United States, de John N. Pomeroy (1868); A treatise on the Constitutional Limitations which Rest Upon the Legislative Power of the States of the American Union (1868) y The general principles of constitutional law in the United States of America (1880), ambas de Thomas M. Cooley; The Common Law, de Oliver Wendell Holmes Jr. (1881); Congressional Government. A Study in American Politics, de Woodrow Wilson (1885); The Doctrine of Judicial Review: Its Legal and Historical Basis and Other Essays (1914)

33 SAgüés, Néstor P., Elementos de derecho constitucional, op. cit., pp. 40.41.

34 Véanse, entre otros, Pollard, David, Parpworth,-Neil y Hughes, David, Constitutional and Administrative Law. Text and Materials, 4* ed., Oxford: Oxford University Press, 2007. 
y The Constitution and what it means today (1920), ambas de Edward Samuel Corwin; y Constitu. tionalism: Ancient and Modern, de Charles Howard Mcllwain (1940). En la actualidad también abundan los textos sobre Constitutional Law, como los de Bernard Schwartz, Gerald Gunther, Geoffrey Stone, Lochhart-Kamisar-Choper-Shiffrin, Laurence H. Tribe, C. Herman Pritchett, Stone-Seidman-Sunstein-Tushnet, Freud-Sutherland-Howe-Brown, Howak-Rotunda-Youg, M. R. Forrester, entre otros.

De esta forma y de manera paralela al procesalismo científico, la ciencia del derecho constitucional surge con las constituciones escritas en los siglos XVIII-XIX ${ }^{35}$ y se desarrolla fundamental. mente en el siglo XX, especialmente cuando se acepta su autonomia de la ciencia política. ${ }^{36}$ Como bien lo señala Pérez Royo "antes de la constitución hay reflexión politico-juridica de alcance constitucional, muy interesante por cierto, pero no hay ni puede haber todavía un intento de estudiar ordenada y metódicamente la nueva forma de articulación jurídica del Estado" ${ }^{37}$

En cambio, su estudio como fenómeno histórico social, como forma de poder y de organización del estado, se remonta a la Grecia antigua. Así puede advertirse de las obras de Aristóteles: Ética a Nicómaco, Politica, y Constitución de Atenas; de Platón: sus Diálogos: Reprública, Politico, y Las leyes; y de Cicerón: Sobre la República, y Las leyes. Con estos autores se inicia el estudio de las instituciones politicas y se prolonga con muchos otras obras y pensadores clásicos a través del tiempo, como La ciudad de Dios, de San Agustin (413-426); Summa Theologica, de Santo Tomás de Aquino (1265-74); Defensor pacis, de Marsilio de Padua (1324); Breviloquium de potestate tyrannica, de Guillermo de Ockham (1346); El príncipe (1513) y Discursos sobre la primera década de Tito Livio (1512-17), de Nicolás Maquiavelo; Utopia, de Santo Tomás Moro (1516); FrancoGallia, de François Hotman (1573); Los seis libros de la República, de Jean Bodin (1576); De Cive (1642) y Leviatán: la materia, forma y poder de un estado eclesiástico (1651), de Thomas Hobbes; El ejercicio de la magistratura y el reinado, de John Milton (1649); Ensayos sobre el gobierno civil, de John Locke (1660-1662); Ensayos sobre moral y politica, de David Hume (1741-42); El espiritu de las leyes, de Charles-Louis de Montesquieu (1748); y El contrato social, de Jean-Jaques Rousseau (1762). Autores y obras universales, entre otras, que influyeron notablémente en el pensamiento politico y especialmente en la filosofia política. Sin embargo, como lo expresa claramente Linares

35 Un panorama interesante de la situación del constitucionalismo a mediados del siglo XIX, puede verse en la obra conmemorativa del centenario de la Constitución mexicana de 5 de febrero de 1857 , en la que participaron un importante número de juristas a nivel mundial. Cfr. AA.VV. El constitucionalismo a mediados del siglo XIX, México, UNAM, II tomos, 1957.

36. En cuanto a los vínculos existentes y diferencias entre la ciencia política y el derecho constitucional, véase Romero, César Enrique, "Ciencia politica, derecho politico y derecho constitucional (aportes didácticos)", en Revista de Estudios Políticos, Madrid: Instituto de Estudios Políticos, núm. 185, septiembre-octubre de 1972 , pp. 269-282.

37 Curso de derecho constitucional, 3a ed., Madrud: Marcial Pons, Ediciones Jurídicas y Sociales, 1996, p. 59. 
Quintana, "la ciencia del derecho constitucional reconoce un origen relativamente reciente, sea porque la idea de la consideración cientifica autónoma de las distintas partes del derecho data de hace poco tiempo, sea por la dificultad metodológica de aislar los problemas juridicos del Estado de aquellos históricos, filosóficos, politicos y sociológicos." 38

De esta forma, puede sostenerse que si bien la ciencia del derecho constitucional surge a partir del siglo XIX, se consolida en el siglo XX y especialmente a partir de la segunda guerra mundial, cuando su estudio se convierte estrictamente jurídico y autónomo de la ciencia política y de otras disciplinas. Se transita de una teoría política constitucional a una dogmática juridica constitucional. Pérez Royo ubica tres periodos en la evolución de la ciencia del derecho constitucional. La primera comprende desde la Revolución francesa hasta la Revolución de 1848, en la cual el derecho constitucional es exclusivamente derecho politico y se estudian los principios del Estado constitucional con un afán proselitista para obtener la victoria sobre el régimen absolutista; la segunda, al consolidarse el Estado constitucional, desde la Revolución de 1848 hasta el inicio de la Primera Guerra Mundial en 1914, periodo en el cual la constitución es considerada como documento político y el derecho constitucional adquiere carácter enciclopédico por su vinculación con las ideas y formas políticas; la tercera, se inicia al finalizar la Segunda Guerra Mundial y en la cual se afirma la concepción de la constitución como norma, de tal suerte que el derecho constitucional se estudia como disciplina jurídica y se escinde de otras disciplinas afines. ${ }^{39}$ En época reciente, incluso, se afirma con gran caudal una corriente denominada "Neoconstitucionalismo", ${ }^{40}$ que podría desembocar en una nueva etapa evolutiva de la ciencia del derecho constitucional.

De todo lo dicho en este epigrafe se advierte que el estudio cientifico del derecho procesal y del derecho constitucional surge a partir de la corriente del derecho público alemán de la segunda mitad del siglo XIX y se consolidan como disciplinas jurídicaš autónomas durante el siglo $\mathrm{XX}$.

\section{EL DERECHO PROCESAL CONSTITUCIONAL COMO FENÓMENO HISTÓ. RICO SOCIAL}

El derecho procesal constitucional comprende también dos realidades: el fenómeno histórico social y su estudio científico.

38 Tratado de la ciencia del derecho constitucional, p. 15. Linares Quintana se apoya en la obra de PALMerinI, Massimo, Introduzione allo Studio del diritto costituzionale, Edizioni dell'Ateneo, 1947, pp. 40-41.

39 Cfr. Perez Royo, Javier, Curso de derecho constitucional, op. cit., pp. 59-62.

40 Sobre esta nueva corriente cientifica, véanse los interesantes trabajos contenidos en Carbonell, Miguel (Edi. tor), Teoria del neoconstitucionalismo. Ensayos escogidos, Madrid: Trotta, 2007; y Neoconstitucionalismo(s), Madrid: Trotta, 2003. 
El primero de ellos comprende el análisis de los instrumentos jurídicos de protección de los derechos humanos o de altos ordenamientos, asi como las jurisdicciones u órganos que conocian de estos mecanismos en las diversas épocas y sistemas juridicos. Asi se estudian las instituciones, medios de defensa, garantias, personajes, jurisdicciones, jurisprudencia, doctrina e ideologias, lo que permite escudrinar sus antecedentes remotos desde la antigüedad. Corresponde a las "fuentes históricas" de la disciplina sean legislativas, jurisprudenciales o ideológicas. A continuación esbozamos el fenómeno histórico social del derecho procesal constitucional sin ningún propósito de exhaustividad, dividiendo su análisis en las cuatro etapas históricas: ${ }^{41}$

I. AntigüEdAd. Advierte Cappelletti algún antecedente remoto en Grecia. Se refiere al precedente ateniense, de la superioridad y rigidez del nómos (que equipara a una especie de ley constitucional) con respecto del pséfisma (que lo considera como un decreto). El pséfisma debía ajustarse al nómos para que fuese legal. El efecto del pséfisma contrario al nómas consistia esencialmente en una responsabilidad penal de quien habia propuesto el decreto a través de una acción pública de un año denominada grafé paranónon, además, el efecto también consistía, por fuerza de principio, en la invalidez del decreto ilegal, es decir, contrario al nómas. ${ }^{42}$

Al estudiar los antecedentes del juicio de amparo mexicano, algunos juristas han encontrado instituciones o antecedentes remotos en dos figuras del derecho romano. En el interdicto pretoriano de Homine libero exhibendo (Ley I, Libro 43, Título 29 del Digesto), consistente en un mecanismo para la defensa de los hombres libres que eran detenidos con dolo, es decir, arbitrariamente por particulares, de tal suerte que se podia exhibir al hombre libre (Quem liberum dolo malo retines, exhibeas) a través de un procedimiento sumarisimo. ${ }^{43}$ José Claudio Ferrier en su Paratitla de los Títulos del Digesto señala: "Con este entredicho compele el pretor al que retiene con dolo -un hombre libre, -que lo presente. No es de asunto particular-de interés meramente privado, sino de oficio y a favor de la libertad. Es exhibitorio. Qué sea exhibir, lo dice el \& 8 de la L. 3 de este título (2). También es popular; pues á nadie se ha de prohibir que pida á favor de la libertad, L. $3 \& 9$ eod.; pero si muchos lo intentan, el pretor elige uno, el mas interesado, el mas idóneo, y quedan los demás escluidós. L 3, \& 13. Se da contra el que dolosamente detiene al hombre libre, L. 1, h; por consiguiente cesa contra el que detiene con justa causa, L. 3, $\& 2$ et seq. H. t., y contra el que detiene, porque el detenido lo quiere, salvo que esté engañado

Consideramos de utilidad dividir el análisis del fenómeno histórico social del derecho procesal constitucional en las cuatro etapas que tradicionalmente se ha dividido la historia: Edad Antigüa (desde la invención de la escritura, 3000 años a.c., hasta la caida del Imperio Romano de Occidente, 476); Edad Media (476 hasta el descubrimiento de América, 1492); Edad Moderna (1492 hasta la revolución francesa, 1789); Edad Contemporánea (1789 hasta nuestros dias).

42 Cappelietti, Mauro, La justicia constitucional (Estudios de Derecho Comparado), México: Porrủa, 1987, pp. 4648.

43 Cfr., entre otros, BurgoA, Ignacio, El juicio de amparo, 33ª ed., México: Porrủa, 1997, pp. 48-49; y Nor!ega, Alfonso, Lecciones de amparo, op. cit., Tomo i, pp. 59.60. 
ó seducido. L. 3, \& 5. Ha de constar para que tenga lugar, que el detenido es libre, ó está en posesión de su libertad. L. $3 \& 7$. L. $4, \& 1$, h. t. Concurre con el juicio de la ley favia contra los plagiarios sin que mutuamente se destruyan, pues el entredicho se dirige á la exhibición, y el procedimiento criminal á la pena y al escarmiento. L. 3, in prin. H. t. Es perpétuo, L. 3, \& últ., y eso se introdujo contra la índole de las acciones populares a favor de la libertad." ${ }^{44}$

Por otra parte, en la República romana se creó el tribunado de la plebe por una demanda y conquista de los plebeyos, a manera de contrapoder de los cónsules. La casa del Tribuno debía estar abierta dia y noche para la defensa de éstos y eran nombrados por la asamblea de la plebe (concilium plebis). El tribunado de la plebe se instituía como sacrosanto (sacrosanctitas), por lo cual tenía protección de cualquier daño. A través de la Intercessio tribunicia, se solicitaba ante el tribunado de la plebe apellatio auxilium en contra de un mandato de los magistrados y la protección se podía extender para anular las leyes. ${ }^{45}$ Este tribuno de la plebe defendia los intereses populares, al impedir la aplicación de las disposiciones legislativas contrarias a dichos intereses (intercessio), otorgando protección personal a los perseguidos por las autoridades (ius auxililii). ${ }^{46}$ Incluso, la intercessio "fue un instrumento clave en la oposición politica llevada a cabo por el tribuno de la plebe frente a las decisiones de los magistrados patricios", ${ }^{47}$ al poder vetar la ley o propuesta del magistrado que incluía otros tribunos de la plebe (ius intercessionis).

II. Edad Media y Edad Moderna. Se ha considerado al Habeas Corpus Amendment Act de 28 de mayo de 1679 , con dieciocho preceptos, como el primer ordenamiento detallado que regula a un proceso constitucional, si bien existió desde la Carta Magna de 1215 y en la Ley Inglesa de $1640 .{ }^{48}$

También en el Reino de Aragón existió una figura encargada de velar por el cumplimiento exacto de los diversos fueros. El Justicia Mayor apareció en el siglo XII y tuvo su esplendor entre los años 1436 y 1520, que incluso se hablaba en esa época de la figura del "Justiciazgo" para comprender al Justicia y a sus Lugartenientes. Conocian fundamentalmente de los procesos forales aragoneses (los de mayor arraigo eran: de inventario, de firma de derecho, de aprehensión y de manifestación de persona). La finalidad de los mismos consistía en la protección o defensa de los súbditos en contra de los actos excesivos y arbitrarios de la autoridad real y eclesiástica, que cons.

44 Ferrier, José Claudio, Paratitla ó exposición compendiosa de los Títulos del Digesto, México: Santiago Pérez, 1853, Tomo II, pp. 139.140 (Edición facsimilar, México: Suprema Corte de Justicia de la Nación, 2007).

45 Cfr. BAtizA, Rodolfo, "Un preterido antecedente remoto del amparo", en Revista Mexicana de Derecho Püblico, núm. 4, abril-junio de 1947, pp. 429-437.

46 Fix-Zamudio, Héctor, y Valencia Carmona, Salvador, Derecho constitucional mexicano y comparado, op. cit., p. 183.

47 Rasón, César, Sintesis de historia e instituciones de derecho romano, $2^{\mathrm{a}}$ ed., Madrid: Tecnos, p. 62.

48 Cfr. Sagüés, Néstor P., "Los desafios del derecho procesal constitucional", en Bazan, Víctor (coord.), Desafios del control de la constitucionalidad, Buenos Aires: Ediciones Ciudad Argentina, 1996, pp. 21-41, en p. 22. 
tituian contrafuero en perjuicio de los mismos. En las Cortes de Tarazona, de 1592, se estableció que el cargo de Justicia dejaba de ser inamovible y podia ser proveído por el rey, así como los nombramientos de los Lugartenientes, lo que provocó el decaimiento de la institución. Los Decretos de Nueva Planta de Felipe V (1707), constituyen el antecedente formal de su desaparición. ${ }^{49}$

Para Cappelletti el antecedente directo del control judicial de las leyes lo fue la batalla de Lord Edward Coke por la supremacia del common law, verificada por los jueces sobre el rey y el parlamento, especialmente el célebre Bonham's Case de 1610. No obstante la doctrina de Coke emanada de este caso y entendida como instrumento de lucha contra el absolutismo del rey o del parlamento, en Inglaterra se consolidó la supremacia del parlamento a partir de la revolución de $1688 .^{50}$ De esta forma estima que el antecedente directo del control judicial de la constitucionalidad de las leyes se debe a la doctrina de Sir Edward Coke, que logró acogida en los Estados Unidos y paradójicamente fue abandonada en Inglaterra y ahora en sus ex colonias, donde ha prevalecido la "supremacia del parlamento" y no la de los jueces. ${ }^{5 !}$

Asimismo, se han encontrado instituciones en el derecho indiano, especialmente como antecedentes del juicio de amparo mexicano. ${ }^{52}$ Los recursos ante las Audiencias de México y Guadalajara; $;^{53}$ el recurso de fuerza; $;^{54}$ el recurso "obedézcase pero no se cumpla"; ${ }^{55}$ el recurso de nulidad por injusticia notoria; ${ }^{56}$ y lo que el historiador del derecho Andrés Lira González ha

49 Sobre los procesos forales aragoneses y el Justicia Mayor existe una amplia bibliografia. Véanse, entre otros, BONET NavarRo, Ángel, Procesos ante el justicia de Aragón, Zaragoza, Guara, 1982; Lopez DE HARO, Carlos, La constitución y libertades de Aragón y el justicia Mayor, Madrid, Reus, 1926, especialmente pp. 1-12, 336-385 y 426-625; FAIRÈN GUILLEN, Victor, Antecedentes aragoneses de los juicios de amparo, México: UNAM, 1971, pp. 7-49. Una síntesis del funcionamiento del Justicia Mayor y de la bibliografia existente, puede verse en nuestra obra La acción constitucional de amparo en México y Esparia (Estudio de derecho comparado), 4an ed., México: Porrúa-UNAM, 2007, pp. 5.18.

so Cappellettr, Mauro, La justicia constitucional (Estudios de Derecho Comparado), op. cit., pp. 48-57.

51 Cfr. CAppellettr, Mauro, "Necesidad y legitimidad de la justicia constitucional", traducción de Luis Aguiar de Luque y Maria Gracia Rubio de Casas, en Favoreu, Louis (editor), Tribunales constitucionales europeos y derechos fundamentales, Madrid, Centro de Estudios Constitucionales, 1984, pp. 599-662, véanse pp. 560-561.

52 Una visión panorámica del derecho indiano puede verse en la obra de Cruz BarneY, Óscar, Historia del derecho en México, 2a. ed., México: Oxford, 2004, pp. 221-544.

53 Sobre las facultades de estas Audiencias, véanse, entre otros, Soberanes FernÁNDEZ, José Luís, Los tribunales de la Nueva España. Antologia, México: UNAM, 1980; de este mismo autor, "Introducción al estudio de la Audiencia de México", en Revista de Investigaciones Jurídicas, año 3, nủm. 3, 1979, pp. 465-476; "La administración superior de justicia en Nueva España”, en Boletín Mexicano de Derecho Comparado, México, año XII, núm. 37, enerorabril de 1980 , pp. 143-200.

54 Cfr, entre otros, Margadant, Guillermo F., "El recurso de fuerza en la época novohispana", en Revista de la Facultad de Derecho de México, núms. 172-174, julio-diciembre de 1990, tomo XL, pp. 99-125.

55 Esquivel Obregón, Toribio, Apuntes para la historia del derecho en México, 2a ed., México: Porrúa, 1984, pp. 266 267.

56 Cfr., entre otros, NORIEGA, Alfonso, Lecciones de amparo, $8^{\text {a }}$ ed., revisada y actualizada por José Luis Soberanes, México: Porrúa, 2004, vol. I, p. 64 . 
bautizado como el "amparo colonial", ${ }^{57}$ tesis seguida por Barragán Barragán ${ }^{58}$ y García Belaunde en el Perú, ${ }^{59}$ cuya naturaleza en realidad corresponde a un interdicto posesorio. El propio Barragán Barragán ha puesto de relieve los cuatro amparos regulados por las Siete Partidas. ${ }^{60}$ Mención especial merece la obra de José Luis Soberanes Fernández y Faustino José Martinez Martinez, denominada Apuntes para la historia del juicio de amparo, que han estudiado con profundidad desde la perspectiva histórica a la institución, desde los amparamientos en las Partidas, los antecedentes aragoneses, anglosajones y coloniales, los origenes constitucionales en Yucatán y de los diversos ordenamientos, su consagración federal de 1847 y 1857 , su polémica durante el siglo XIX, hasta su consagración definitiva en la actual constitución 1917. ${ }^{61}$

III. EdAd contemporánea. En este periodo se desarrollan las constituciones escritas. Las ideas de John Locke y de Montesquieu sobre la división del poder encuentran acogida y sirven para el establecimiento de los derechos fundamentales y la limitación del poder en el constitucionalismo contemporáneo. Se consagra el principio de supremacía constitucional en el artículo VI de la Constitución de los Estados Unidos de 1787. Ya Hamilton comentaba este principio en El Federalista al sostener que la Constitución es de hecho una ley fundamental y asi debe ser considerada por los jueces, de tal manera que "debe preferirse la Constitución a la ley ordinaria, la intención del pueblo a la intención de sus mandatarios". ${ }^{2}$

El punto de inflexión del fenómeno histórico social, en su dimensión contemporánea, se suele ubicar en el paradigmático caso Marbury vs. Madison resuelto por la Suprema Corte de los Estados Unidos el 24 de febrero de 1803, por el Chief Justice John Marshall ${ }^{63}$ y especialmente a través de la repercusión de la judicial review of legislation a nivel mundial. Si bien, como lo señala Grant, el control judicial de las leyes no es propiamente una invención norteamericana, sino más bien la aplicación, en las constituciones escritas, de loś principios y de las técnicas desarrolladas por el common law inglés para impedir que las corporaciones públicas y privadas

Cfr. LiRA Gonzalez, Andrés, El amparo colonial y el juicio de amparo mexicano. Antecedentes novohispanos del juicio de amparo, México: Fondo de Cultura Económica, 1972.

58 Cfr. Barragán barracán, José, "Los reales amparos", en su obra Temas del liberalismo gaditano, México, UNAM, $1978, \mathrm{pp}$.

59 Cfr. Garcla Belaunde, Domingo, "El amparo colonial peruano", en su obra Derecho procesal constitucional, Bogotá: Temis, 2001, pp. 79-87.

60 Cfr., su libro Algunas consideraciones sobre los cuatro recursos de amparo regulados por las Siete Partidas, 2a ed., Guadalajara: Universidad de Guadalajara, 2000.

61 Cfr. Soberanes Fernández, José Luis, y Martinez Martinez, Faustino, Apuntes para la historia del juicio de amparo, México: Porrúa, 2002.

62 Op. cit., p. 332.

63 Existe una bibliografía impresionante sobre Marshall y especialmente del famoso fallo de 1803. Una biografia moderna puede verse en SMrth, Jean Edward, John Marshall. Definer of a nation, Nueva York: Henry Holt, 1996. 
traspasaran el campo de su autoridad. ${ }^{64}$ Incluso antes de ese famoso y trascendental fallo de Marshall, el tribunal de New Jersey en el caso Holmes us. Walton (1780), resolvió un caso de inconstitucionalidad de un estatuto local y provocó incluso que la legislatura aceptara el criterio procediendo a su reforma. Esa práctica ya se realizaba en las entidades federativas. El Juez Wythe, maestro de Marshall y que integraba el tribunal de Apelación de Virginia, entendia ese poder de los jueces sobre la legislatura si traspasaba los limites que el pueblo le ha impuesto en la constitución (caso Commonwealth vs. Caton, de $1782 .{ }^{65}$

Cappelletti advierte la influencia del control judicial de las leyes estadounidense y señala una tendencia evolutiva común y universal del fenómeno, tanto en el common law como en el civil law, distinguiendo tres etapas o épocas, a manera de una dialéctica hegeliana (tesis, antitesis y sintesis), que denominó como "derecho natural", "derecho legal" y "justicia constitucional". En los paises del common law, surge la primera etapa derivada del pensamiento de Coke, si bien implicita cuatro siglos antes en Bracton, consistente en la supremacía del common law; la segunda época, con la Revolución de 1688, en la que se olvida la enseñanza de Coke y prevalece la supremacia del parlamento sobre la superioridad del common law; y la tercera, cuando surgen las constituciones escritas y se establecen en los Estados Unidos de Norte América las cortes supremas para hacer prevalecer la higher law, a partir del paradigmático caso resuelto por la Corte Suprema de 1803, si bien con ciertos precedentes anteriores resueltos por las cortes supremas estatales como el propio Marshall lo señala. ${ }^{66}$

Esta tendencia evolutiva también puede advertirse en la familia jurídica de base romanística. En el civil law, estimaba que se pueden ubicar también estas tres etapas, si bien en épocas posteriores: la primera, en el que las escuelas iusnaturalistas proclamaban la inaplicabilidad de leyes contrarias al derecho natural. Así lo advertia, por ejemplo, de la doctrina de la Hereuse im. puissance (feliz impotencia) del rey de violar las lois fondamentales du royaume, es decir, la doctrina francesa de la inviolabilidad de las leges imperii. Esta conecepción del jus naturale que arraigó de manera importante, lo vinculaba con el pensamiento de Platón y de Aristóteles, y particularmente con la doctrina tomística, los filósofos estoicos y a Cicerón. Consideró que de alguna forma constituia un precedente valioso de lo que siglos después se consolidó en el control de la constitucionalidad de las leyes. En la segunda etapa prevaleció el principio de legalidad, mientras que en la tercera el pensamiento de Kelsen al establecer cortes especializadas para interpretar las constituciones. ${ }^{67}$

${ }^{64}$ Grant, J.A.C., "La Constitución de los Estados Unidos", en El constitucionalismo a mediados del siglo XIX, México: UNAM, 1957, pp. 691.730.

5 Op. cit., p. 703-704.

* Cappellettr, Mauro, Proceso, ideologias, sociedad, trad. de Santiago Sentis Melendo y Tomás A. Banzhaf, Buenos Aires: EJEA, 1974, pp. 461-467.

67 Ibidem, pp. 464-465. 
En este periodo debe también mencionarse las ideas del abate Sieyès y el Senado Conservador de la Constitución francesa de 1799 , que tuvieron impacto en el siglo XIX y en el pensamiento de Carl Schmitt. Según este autor, a la muerte de Cormwell (1658) y después de los primeros ensayos modernos de constituciones escritas, se propuso una corporación especial, a manera del eforato espartano, que viniera a mantener la ordenación existente del Commonwealth y a impedir la restauración de la monarquía. Encontraron ahi su origen las ideas referentes a un "defensor de la libertad" y luego a un "defensor de la Constitución", que se abrieron paso en el circulo de Harrington. Dice Schmitt que "Ahi tiene su origen la idea de aquellas que, a través de las cartas constitucionales de Pensilvania, llegan hasta las de la Revolución francesa. En Francia, en la Constitución del año VIII (1799) aparece el Senado como defensor (conservateur) de la Constitución. En este caso, también, semejante instituto precede inmediatamente a una reacción política, la de la época de Napoleón I. Por esto es doblemente interesante comprobar que el Sénat conservateur no desempeñó su papel tutelar de la Constitución hasta la derrota militar de Napoleón, cuando por decreto de 3 de abril 1814 declaró que Napoleón y su familia quedaban desposeídos del trono por haber vulnerados la Constitución y los derechos del pueblo". ${ }^{68}$ Las argumentaciones de Schmitt, por supuesto, están encaminadas a defender su postura ideológica relativa al decisionismo politico y es por ello que acoge la doctrina de Banjamín Constant relativas al órgano moderador u órgano neutro o armónico, como veremos en su oportunidad.

Los antecedentes en estos cuatro periodos históricos sólo representa un bosquejo sin entrar en mayor detalle y en otros precedentes como los existentes en Latinoamérica en el denominado sistema Colombo-Venezolano de control constitucional de leyes (1850-58) o la instauración del juicio de amparo en la Constitución del Estado de Yucatán de 1841. Hemos tratado simplemente de señalar algunas de las instituciones, figuras, etapas, ideologias y momentos relevantes y significativos en el derecho procesal constitucional como fenómeno histórico social, a manera de "fuentes históricas" de la disciplina, que como sucede en otras áreas del conocimiento, su estudio dogmático se desarrollaría después.

\section{EL DERECHO PROCESAL CONSTITUCIONAL COMO CIENCIA: CUATRO ETAPAS DE DESARROLLO}

La ciencia del derecho procesal constitucional, o si se prefiere, la dogmática del derecho procesal constitucional, en cambio, adquiere relevancia a partir de la creación de los tribunales constitucionales europeos. Especialmente de la Corte Constitucional austríaca de 1920 y particularmente a partir del influyente estudio de Hans Kelsen de 1928, como veremos más

La defensa de la constitución. Estudio acerca de las diversas especies y posibilidades de salvaguardia de la constitución, trad. de Manuel Sánchez Sarto, 2ª ed., Madrid: Tecnos, 1998, pp. 27.28. 
adelante. Este influyente ensayo podría representar lo que la obra de Bulöw para el derecho procesal o la de Gerber para el derecho constitucional, al desencadenar el comienzo de una nueva concepción dogmática y que repercutiria después en la autonomia científica de sus disciplinas. Esto no significa ignorar la importancia de otros trabajos anteriores, muy valiosos por cierto, pero que no tuvieron el impacto que causó aquel trabajo precursor de Kelsen sobre la garantía jurisdiccional de la Constitución, basamento sobre el cual se construyó lo que hoy se conoce como derecho procesal constitucional en su dimensión cientifica.

Con la polémica idiológica Schmitt-Kelsen sobre el guardián de la constitución, los planteamientos del segundo se consolidaron y se dieron ampliamente a conocer, surgiendo una nueva corriente dogmática. A partir de ahí se inicia una transición a la luz de la corriente del procesalismo científico. Primero al advertir su existencia como disciplina autónoma, luego su desarrollo dogmático, hasta llegar a su sistematización cientifica como rama procesal. De tal suerte que es en este periodo donde debemos ubicar el nacimiento del derecho procesal constitucional como ciencia (1928-1956).

La construcción cientifica de las disciplinas constituye una secuencia concatenada del pensamiento al ir construyendo, con base en los predecesores e influjos sociales, politicos y jurídicos del momento, nuevas concepciones y teorias. El propio Alcalá-Zamora así lo advierte para la evolución de la doctrina procesal. Reconoce que las etapas culturales no son compartimientos estancos sino momentos capitales enlazados entre si. ${ }^{69} \mathrm{Y}$ es por ello que consideramos de mayor provecho ubicar el periodo histórico en el cual surge la disciplina del derecho procesal constitucional, destacando las contribuciones de sus distintos forjadores.

Para una mayor claridad se pueden advertir cuatro etapas concatenandó las contribuciones de estos insignes juristas, hasta llegar a su configuración sistemática como discipłina autónoma procesal:

A). PrECURSORA (1928-1942). Se inicia con el trabajo de cimentación teórica de Kelsen, relativo a las garantias jurisdiccionales de la Constitución (1928) y al reafirmarse su postura con la polémica que sostuvo con Carl Schmitt sobre quién debería ser el guardián de la Constitución (1931). En este periodo y en el exilio Kelsen publica en los Estados Unidos un ensayo de corte comparativo entre los controles de constitucionalidad de las leyes austriaco y norteamericano $(1942),{ }^{70}$ que constituye el primero en su género, por lo que si bien no tuvo un impacto signifi-

Cfr, "Evolución de la doctrina procesal", op. cit., p. 293.

70 Kelsen, Hans, "Judicial Review of Legislation. A Comparative Study of the Austrian an the American Constitution", en The Journal of Politics, vol. 4, núm. 2, mayo de 1942, pp. 183-200. Existe traducción al español por Domingo García Belaunde, "El control de la constitucionalidad de las leyes. Estudio com- 
cativo resulta de utilidad para la disciplina cientifica.

B) Descubrimiento procesal (1944-47). El procesalista español Niceto Alcalá-Zamora y Castillo, en sus primeros años de exilio en Argentina (1944-45) y luego en México (1947), advierte la existencia de una nueva rama procesal y le otorga denominación. En Argentina al titular su obra Estudios de derecho procesal (civil, penal y constitucional) en 1944; y al año siguiente de manera expresa señala que la institución del amparo debe ser considerada dentro del derecho procesal constitucional, en una reseña que realiza a un comentario de un libro en la Revista de Derecho Procesal (1945). Y en México en las referencias que realiza en su clásica obra Proceso, autocomposición y autodefensa (contribución al estudio de los fines del proceso) en 1947.

C) Desarrollo dogmático procesal (1946-55). Etapa en la cual el mejor procesalismo cientifico de la época realiza importantes contribuciones para acercarse a la tendencia del constitucionalismo. Es el periodo del estudio de las garantias constitucionales del proceso iniciada por Couture (1946-48) y del análisis de la jurisdicción constitucional e instrumentos procesales de control a través de las colaboraciones de Calamandrei (1950-56) y Cappelletti (1955). Couture inicia toda una corriente dogmática en el estudio de las garantías constitucionales del proceso, especialmente del proceso civil, pero utiliza la expresión "garantía" como sinónimo de derecho fundamental y no como mecanismo procesal de defensa. Calamandrei estudia el fenómeno de la jurisdicción constitucional a la luz del procesalismo científico, realizando clasificaciones muy valiosas sobre la caracterización de los sistemas de justicia constitucional y analizando especialmente los efectos de las sentencias constitucionales, pero no lo realiza en su integridad ni advierte la existencia de la disciplina. Cappelletti agrupa el estudio de los instrumentos procesales de protección jurisdiccional de los derechos fundamentales en la categoría que denomina "jurisdicción constitucional de la libertad" que con el paso del tiempo se ha aceptado y luego desarrolla su teoria en el ámbito supranacional, pero no emplea la expresión ni advierte la existencia de una nueva rama procesal.

D) DEFINICIÓN CONCEPTUAL Y SISTEMÁTICA (1955-56). El último eslabón constituye la definición conceptual como disciplina procesal y la realiza Fix-Zamudio en su trabajo relativo a La garantia jurisdiccional de la constitución mexicana. Ensayo de una estructuración procesal del amparo (1955), publicado parcialmente al año siguiente en diversas revistas mexicanas (1956).

parado de las constituciones austriaca y norteamericana", en lus et Veritas, Lima, Pontificia Universidad Católica del Perú, año VI, núm. 6, 1993, pp. 81-90. Esta última traducción se reproduce en Argentina con nota introductoria de Germán J. Bidart Campos, en El Derecho, Buenos Aires, año XXXII, número 8435, 14 de febrero de 1994, pp. 1.5; así como en España, con nota introductoria de Francisco Fernández Segado, en Direito. Revista Xurídica da Universidade de Santiago de Compostela, vol. IV, núm. 1, 1995, pp. 213-231. 
Las aportaciones de aquellos juristas son fundamentales para fraguar el primer estudio dedicado "al análisis de la disciplina científica como objeto de estudio específico" y con la intención de sistematizarla a partir de su naturaleza procesal. Se debe al jurista mexicano Héctor Fix-Zamudio que, recogiendo el hallazgo de su maestro y utilizando el trabajo precursor de Kelsen de 1928 así como las aproximaciones científicas de Calamandrei, Couture y Cappelletti, define y le otorga los contornos cientificos a la disciplina, determina su naturaleza jurídica, la conceptualiza dentro del derecho procesal inquisitorial, le otorga un contenido especifico y la distingue de lo que es propio del derecho constitucional. Y lo hace en su tesis para lograr el grado de licenciado en derecho (1955), cuyos capitulos fueron publicados por separado al año siguiente en diversas revistas mexicanas (1956).

No se puede dudar de la aportación kelseniana al sentar las bases teóricas sobre las cuales descansa la jurisdicción constitucional, en su dimensión concentrada de control de la constitucionalidad, asi como la repercusión que causó su estudio de 1928 en la concepción del derecho en general y particularmente en el desarrollo del derecho constitucional. Sus aportaciones a la teoría general del derecho fueron de tal magnitud que influyeron en toda la concepción del derecho y de sus ramas. Es el precursor del derecho procesal constitucional, al establecer los cimientos de lo que vendria después: la acogida de su postulado en el seno mismo del procesalismo cientifico. Kelsen sembró la semilla. Alcalá-Zamora descubre el pequeño retoño. Couture, Calamandrei y Cappelletti hacen que broten sus primeras ramas. Fix-Zamudio le da la forma para convertirlo en un árbol lo suficientemente visible para que otros lo advirtieran y bajo su sombra se cobijen.

Las aportaciones científicas de Couture, Calamandrei y Cappelletti, desde diversos ángulos acercaron el procesalismo a la corriente del constitucionalismo de la época y resultaron fundamentales para ir configurando procesalmente el fenómeno, hasta llegar a la sistematización integral de la disciplina cientifica que realiza Fix-Zamudio con base en aquellos desarrollos.

Estos juristas influyeron notablemente en Fix-Zamudio, pero se debe a él su primer acercamiento conceptual y sistemático como disciplina autónoma procesal. Las contribuciones de estos eminentes procesalistas no se realizaron pensando en la "nueva disciplina" como tal, si bien contribuyeron notablemente en diversos aspectos de su contenido y teniendo en cuenta la cimentación teórica de Kelsen.

De lo anterior se sigue que a pesar de las notables aportaciones de Couture, Calamandrei y Cappelletti, ninguno advirtió la existencia de la "nueva rama procesal", como sí lo hicieron Alcalá-Zamora y Fix-Zamudio. Maestro y discípulo deben ser considerados como los fundadores del derecho procesal constitucional entendida como disciplina autónoma procesal, si bien el primero en su dimensión "nominal o formal" (siguiendo la tesis de García Belaunde) y el 
segundo en su aspecto "conceptual o material". Uno "descubrió" la existencia de la disciplina cientifica y el otro le otorga "contenido sistemático", con la intención manifiesta de definir su naturaleza y perfil como rama autónoma procesal.

Fix-Zamudio es el primer jurista que define al derecho procesal constitucional como: "la disciplina que se ocupa del estudio de las garantias de la Constitución, es decir, de los instrumentos normativos de carácter represivo y reparador que tienen por objeto remover los obstáculos existentes para el cumplimiento de las normas fundamentales, cuando han sido violadas, desconocidas o existe incertidumbre acerca de su alcance o de su contenido, o para decirlo con palabras carnelutianas, son las normas instrumentales establecidas para la composición de los litigios constitucionales" ${ }^{71} \mathrm{Si}$ bien podría discutirse si esa concepción comprende el contenido integral de la disciplina, lo cierto es que representa la primera definición a manera de aproximación científica y en la cual se incorpora como objeto de estudio de la misma a las "garantías constitucionales" que hoy en dia es indiscutible que son parte esencial de su contenido.

Como bien señala Garcia Belaunde en su sugerente tesis, "para hablar de un fundador del Derecho Procesal Constitucional, necesitamos por un lado que exista el Derecho Procesal; por otro que lo adjetivemos, o sea, que le demos el nombre y finalmente le demos el contenido". ${ }^{72}$ $\mathrm{Y}$ eso es precisamente lo que hicieron maestro y discípulo. Alcalá-Zamora le otorga nomen iuris al advertir su existencia (1944-47) y Fix-Zamudio desarrolla el descubrimiento de su maestro, al precisar su naturaleza y definir su configuración científica (1955-56). Ambos lo hacen de manera consciente pensando en la "disciplina cientifica" como "rama procesal". Por supuesto que el jurista mexicano sistematiza la disciplina a partir del hallazgo de su maestro, de las bases teóricas de Kelsen y en la misma sintonía de la corriente del procesalismo cientifico que se había acercado al fenómeno constitucional (Couture, Calamandrei y Cappelletti).

Couture, por una parte, utiliza la expresión desde 1948 en su clásico Estudios de derecho procesal civil. La "Parte Primera" y "Parte Tercera" del tomo I, llevan los títulos: "Tutela constitucional de la justicia" y "Casos de derecho procesal constitucional". Si nos detenemos en la lectura de su contenido, se advierte que en realidad se refiere, en términos generales, a las dimensiones constitucionales del proceso civil y del debido proceso, lo que ocasionó una nueva dimensión en cuanto al análisis dogmático de las instituciones procesales con trascendencia constitucional. Esta es una aportación fundamental dentro del procesalismo contemporáneo, que llevó años más tarde a que el propio Fix-Zamudio lo considerara como el fundador de una

71 FIX-Zamudio, Héctor, La garantia jurisdiccional de la Constitución mexicana. Ensayo de una estructuración procesal del amparo (tesis de licenciatura), 1955, op. cit., pp. 90.91.

72 García Belaunde, Domingo, "Dos cuestiones disputadas sobre el derecho procesal constitucional", op. cit., p. 142. 
disciplina limitrofe que denominó "Derecho Constitucional Procesal", perteneciente a la ciencia constitucional, ${ }^{73}$ materia a la cual nos hemos referido y a la que regresaremos al analizar esta aportación por el jurista uruguayo. Esa es una de las aportaciones más significativas de Couture al procesalismo cientifico, al guiar lo que hoy se ha consolidado como las garantias constitucionales del proceso. Sin embargo, no se advierte que el jurista uruguayo tuviera la intención de otorgarle al derecho procesal constitucional la connotación que luego adquirió ni mucho menos que quisiera sistematizarla como "disciplina procesal".

Como veremos en los siguientes epigrafes, tampoco se ve la referida intención en Calamandrei o en su discipulo Cappelletti. Ambos con importantes contribuciones al contenido de la disciplina, pero sin el afán de su configuración cientifica. Las aportaciones del profesor florentino se advierten en la influencia que tuvo para la consagración de la Corte Constitucional en la Constitución italiana de 1947 y especialmente por la redacción de importantes ensayos entre 1950 y 1956 (año de su sensible pérdida), como son: L'illegittimità costituzionale delle leggi nel processo civile (1950), La Corte costituzionale e il processo civile (1951), Corte Costituzionale e Autorità giudiziaria (1956) y La prima sentenza della Corte costituzionale (1956), entre otros. Estos trabajos resultan relevantes para el estudio dogmático del proceso constitucional. Aproximan el enfoque procesalista al fenómeno de la jurisdicción constitucional, que pareciera luego abandonarse y reconducirse por el enfoque constitucionalista, especialmente a partir de la entrada en funcionamiento de la Corte Costituzionale en 1956. Una de las principales aportaciones del maestro florentino es la clásica caracterización de los dos sistemas de control constitucionales: el difuso como "incidental, especial y declarativo" y el concentrado como "principal, general y constitutivo", distinción que si bien debe matizarse en la actualidad, sigue siendo el punto de partida para cualquier reflexión sobre el particular. ${ }^{74} \mathrm{Sin}$ embargo, el maestro de Florencia, a pesar de esta notable aportación y de un detenido análisis de en los efectos de las sentencias constitucionales, no visualizó la nueva parcela jurídico procesal como "disciplina científica", por lo que nunca utilizó la expresión ni pudo entonces realizar una aproximación sistemática de la misma, si bien contribuyó notablemente en su contenido.

Asimismo, Cappelletti tuvo un primer acercamiento al haber publicado con tan solo 28 años de edad (1955) su primera obra: La giurisdizione costituzionale delle libertà: primo studio sul ricorso

73 Cfr. Fix-Zamudio, Hẻctor, "Reflexiones sobre el derecho constitucional procesal mexicano", en Memoria de El Colegio Nacional 1981, México: El Colegio Nacional, 1982, pp. 37-91.

74 Cfr. Calamandrei, Piero, La ilegittimità costituzionale delle leggi, Padua, CEDAM, 1950, pp. 5 y ss.; existe traducción por Santiago Sentis Melendo, "La ilegitimidad constitucional de las leyes en el proceso civil", en sus ensayos reunidos Instituciones de derecho procesal civil (Estudios sobre el proceso civil), Buenos Aires: El Foro, 1996, vol. III, pp. 21 y ss. 
costituzionale, ${ }^{75}$ que seis años más tarde tradujera Fix-Zamudio al español: La Jurisdicción constitucional de la Libertad. Con referencia a los ordenamientos alemán, suizo y austriaco. ${ }^{76}$ Esta obra representa un riguroso estudio de corte comparativo relativo al análisis sistemático de los diversos instrumentos de protección de los derechos fundamentales. La terminología relativa a la jurisdicción constitucional de la libertad fue acogida por Fix-Zamudio y la considera como uno de los sectores de la disciplina, junto con la dimensión "orgánica" y la "transnacional" que tanto estudió e impulsó el profesor Cappelletti en sus estudios comparatistas a nivel mundial. ${ }^{77}$ En los años siguientes aparecieron varias publicaciones trascendentales a través de la vinculación del proceso y la constitución, como se advierte de su obra La pregiudizialità costituzionale nel proceso civile (1957), así como la voz "Amparo" (1958) en la Enciclopedia del Diritto, ${ }^{78}$ y que fue traducida al castellano en ese mismo año en el Boletin del Instituto de Derecho Comparado en México por el propio Fix-Zamudio. ${ }^{79}$

Sin embargo, las colaboraciones de Couture, Calamandrei y Cappelletti sólo encuentran sentido con el trabajo de cimentación teórica de Kelsen a manera de "precursor" de la disciplina cientifica procesal, en la medida en que inició los estudios dogmáticos en la salvaguarda de la Constitución. Fix-Zamudio ha considerado el ensayo de 1928 de Kelsen como la obra fundacional del derecho procesal constitucional, como lo fue el tratado de Oscar Büllow sobre La teoría de las excepciones dilatorias y los presupuestos procesales (1968), para el derecho procesal civil y podriamos decir de algún modo la obra de Gerber sobre los Fundamentos de un sistema del derecho político alemán (1965) para el derecho público y especialmente para el derecho constitucional. Sin embargo, estos estudios marcaron el inicio de una nueva concepción dogmática y especialmente repercutieron para que después se llegara a la autonomía científica de sus diversas disciplinas. Así sucedió con el derecho procesal y el derecho constitucional, que alcanzaron tal carácter hasta el siglo XX. De la misma manera puede decirse del derecho procesal constitucional. El estudio del fundador de la escuela de Viena repercutió con posterioridad en la dogmática procesal. Resultó fundamental para que se iniciara el análisis dogmático de las categorias procesales è sede constitucional y de los instrumentos procesales de control constitucional (Couture, Calamandrei y Cappelletti, 194656) y para visualizar la existencia de una nueva disciplina procesal en su estudio (Alcalá-Zamora y Castillo, 1944-47), hasta otorgarle su configuración cientifica (Fix-Zamudio, 1955-56).

75 Milán: Giuffrè, 1955.

16 México: UNAM, 1961.

77 A los tres sectores señalados, nosotros hemos agregado un cuarto que denominamos "Derecho procesal constitucional local", entendido como aquel que estudia los distintos instrumentos encaminados a la protección de los ordenamientos, constituciones o estatutos de los estados (en los regimenes federales), provincias o comunidades autónomas. Cfr. Ferrer MAC-GREGor, Eduardo, Los tribunales constitucionales en Iberoamérica, México, Fundap, 2002, pp. 53-54; asimismo, "Hacia un Derecho procesal constitucional local en México", en Anuario Latinoamericano de Derecho Constitucional, Montevideo: Fundación Konrad Adenauer, 2003, pp. 229-245. Editada por Dott. Antonino Giuffrè, Tomo I, 1958.

79 "Voz Amparo", trad. de Héctor Fix-Zamudio en Boletin del Instituto de Derecho Comparado de México, Año XI, septiembre-diciembre de 1958, núm. 33, pp. 63-66. 
Los estudios de cimentación teórica de Gerber (1865), Bullow (1868) y Kelsen (1928), marcan el comienzo de la etapa cientifica del derecho constitucional, derecho procesal y derecho procesal constitucional. Etapa científica que paulatinamente fue consolidándose con otros estudios posteriores teniendo en cuenta aquellos trabajos pioneros. Para el derecho constitucional (y en general para las ramas del derecho público) se han considerado fundamentales las obras de Vittorio Émmanuele Orlando Los criterios técnicos para la reconstrucción del derecho público (1885) y Principii di diritto costituzionale (1889), asi como la obra de Georg Jellinek, Teoria general del estado (1900), siguiendo construyendo la dogmática jurídica constitucional discipulos de Orlando, como Santi Romano y la escuela italiana; contribuyendo notablemente la escuela francesa de derecho constitucional, con autores como Marcel Hauriou, R. Carré de Malberg, Leon Duguit, Maurice Duverger, entre muchos otros. Mientras para el desarrollo del procesalismo científico son fundamentales las obras y polémicas sobre la acción procesal de Windscheid-Muther (195657), anterior a la obra de Bülow, las aportaciones científicas de Kohler: El proceso como relación jurídica (1988) y de Wach: La pretensión de declaración: un aporte a la teoría de la pretensión de protección del derecho, hasta la famosa prolusión de Giuseppe Chiovenda (1903) sobre La acción en el sistema de los derechos donde perfila los conceptos fundamentales de la ciencia procesal. De ahí seguirian construyendo la disciplina muchos otros como sus discípulos Piero Calamandrei y Francesco Carnelutti o en América Ramiro Podetti y Eduardo J. Couture.

Asi puede también considerarse en el derecho procesal constitucional. El estudio precursor lo es el multicitado de Kelsen sobre las garantías jurisdiccionales de la constitución de 1928. No sólo por sentar las bases teóricas sobre la jurisdicción constitucional como órgano concentrado, sino por la repercusión que provocó su estudio dogmático derivada de la polémica con Carl Schmitt sobre el guardián de la Constitución (1931), que llevó al establecimiento y consolidación paulatina de los tribunales constitucionales a partir de la segunda posguerra. Y a partir de ahí siguieron obras que continuaron en su desarrollo desde la dogmática procesal, como se advierte de las publicaciones de Couture, Las garantias constitucionales del proceso civil (1946); de Alcalá-Zamora y Castillo, Proceso, autocomposición y autodefensa (1947); de Calamandrei, L'illegittimità costituzionale delle leggi nel processo civile (1950); y Cappelletti La giurisdizione costituzionale delle libertà: primo studio sul ricorso costituzionale (1955); hasta llegar al primer estudio sistemático del derecho procesal constitucional como ciencia, emprendido por Fix-Zamudio: La garantia jurisdiccional de la constitución mexicana (1955). Este ensayo no sólo se limita al análisis de las garantías en México, como pudiera inferirse del titulo, sino que establece un marco teórico conceptual y sistemático de la disciplina jurídica, a manera de último eslabón en su configuración cientifica. Es por ello que debe considerarse al jurista mexicano como "fundador conceptual" de la ciencia del derecho procesal constitucional, en el entendido de que la "ciencia" se va construyendo a través del pensamiento concatenado de todos estos juristas. 
La postura teórica de Fix-Zamudio tardó en darse a conocer. Probablemente debido a que su inicial trabajo de 1955, que constituye su tesis de licenciatura, apareció en publicaciones dispersas en 1956 siendo hasta 1964 cuando se publica íntegra junto con otros estudios en su libro El Juicio de Amparo. En los siguientes años los rumbos en el análisis científico de la jurisdicción y procesos constitucionales se encaminaron bajo la ciencia constitucional, no obstante que en Itaila los procesalistas iniciaron su estudio dogmático a partir de la Constitución de 1947 hasta los primeros años de funcionamiento de la Corte Costituzionale. ${ }^{80}$ ¿Por qué razón los procesalistas se apartaron de su estudio? Es una respuesta que debería ser analizada con detenimiento y materia de un diverso ensayo.

Esta tendencia se ha mantenido en el viejo continente. Salvo excepciones, pareciera que el estudio sistemático de los procesos, jurisdicción y órganos de naturaleza constitucionales se encuentra (auto) vedada para los procesalistas, debido a su anclaje como parcela del derecho constitucional. Si bien existe una tendencia para estudiar algún proceso constitucional en particular o uno de sus componentes, siguen resultando escasos los estudios integrales del derecho procesal constitucional como corriente del procesalismo cientifico contemporáneo. En Europa ha predominado la visión constitucionalista bajo la denominación "justicia constitucional". Sin embargo, se ha utilizado también la expresión "derecho procesal constitucional" aunque con muy diversos significados y algunas veces como sinónimo de aquélla, siendo pocos los casos que le dan la significación dentro de la corriente procesal, como ha sucedido en España, con procesalistas como Jesús González Pérez, José Almagro Nosete, Victor Fairén Guillén y María del Calvo Sánchez. En otros países se le dan connotaciones diversas a la expresión, como en Alemania: Michael Sachs, Christian Hillgruber, Christoph Goos, C. F. Müller, Roland Fleury, Ernet Benda, Hubertus Gerdsdorf y Christian Pestalozza; en ITal.IA: Gustavo Zagrebelsky, Alessandro Pizzorusso, Roberto Romboli, Antonio Ruggeri, Marilisa D'Amico y Antonio Spadaro; o bien en Portugal: Jose Joaquim Gomes Canotilho, Guilherme da Fonseca, Inês Domingos y Jorge Miranda. ${ }^{81}$

En Latinoamérica, a partir de la década de los setenta del siglo pasado, la semilla científica sembrada retoma nuevos brotes por los que podríamos denominar forjadores de segunda generación. Curiosamente por dos constitucionalistas: Domingo Garcia Belaunde y Néstor Pedro Sagüés. El primero en el Perú, al advertir la existencia de la disciplina cuando emprende un análisis sobre el hábeas corpus en su país (1971); ${ }^{82}$ y el segundo en Argentina, al estudiar la

90 Especialmente por los procesalistas en materia civil. Asi lo advertía Alcalá-Zamora y Castillo. Cfr. "La protección procesal internacional de los derechos humanos", en AA.VV., Veinte años de evolución de los derechos humanos, México: UNAM, 1974, pp. 275-384, en p. 278.

81 Véase supra, la bibliografia citada en el epígrafe IV: "Hacia la consolidación de una nueva disciplina autónoma".

82 El hábeas corpus interpretado, Lima: Instituto de Investigaciones Juridica de la Pontificia Universidad Católica del Perú, 1971, p. 21. 
institución del amparo (1979) ${ }^{83}$ En la década de los ochenta y noventa desarrollan su contenido aceptando implícita o directamente la postura inicial de Fix-Zamudio de 1955-56, sobre su autonomía procesal. A través de importantes publicaciones, organización de seminarios, congresos, conferencias y enseñanza universitaria, dan a conocer la disciplina y han contribuido de manera importante en su desarrollo cientifico.

Domingo Garcia Belaunde si bien discrepa en cuanto al contenido que en los años sucesivos le ha otorgado Fix-Zamudio relativo a la distinción con otra rama limitrofe que denomina "derecho constitucional procesal", lo cierto es que acepta sin ambages y defiende con argumentos sólidos y propios la postura esencial del jurista mexicano: la naturaleza procesal de la disciplina. ${ }^{84}$ Por su parte, Néstor Pedro Sagüés también acoge la vertiente procesal del derecho procesal constitucional y acepta a su vez la confluencia del "derecho constitucional procesal" como materia de la ciencia constitucional, si bien advierte "mutaciones y zonas comunes" que conlleva la posibilidad del análisis "mixto" de los institutos.

Estos forjadores de segunda generación se han convertido en genuinos embajadores del derecho procesal constitucional a lo largo y ancho de Latinoamérica. Han formando "escuela" en sus respectivos paises y en general en nuestro continente. Esto ha llevado incluso a la formación de institutos o asociaciones cientificas como el Instituto lberoamericano de Derecho Procesal Constitucional, cuyo presidente es Sagüés y uno de sus vicepresidentes García Belaunde.

Por supuesto que al lado de ellos han destacado importantes juristas latinoamericanos que aceptan la corriente cientifica del derecho procesal constitucional con diversos matices y contenidos, con importante obra escrita como Osvaldo Alfredo Gozaini (Argentina),-Humberto Nogueira Alcalá (Chile) y Rubén Hernández Valle (Costa Rica). Asimismo, debe también destacarse los siguientes autores: ARGentina: Victor Bazán, Enrique A. Carelli, Juan Carlos Hitters, Fernando M. Machado, Pablo Luis Manili, Mario Masciottra, Adolfo Rivas, Sofia Sagüés y Maria Mercedes Serra. Bolivia: Jorge Asbun, René Baldivieso, José Decker y José Antonio Rivera Santivañez. BrasiL: Marcelo Cantonni de Oliveira, Paulo Roberto de Gouveia Medina, Paulo Hamilton Siqueira Junior, José Alfredo de Oliveira Baracho, Marcus Orione Gonçalvez Correia, Gustavo Rabay Guerra, Roberto Rosas y Willis Santiago Guerra Filho. CHILE: Andrés Bordali Salamanca, Juan Colombo Campbell, Alfonso Perramont y Francisco Zúñiga. ColomBIA: Anita Giacomette Ferrer, Javier Henao Hidrón, Hernán Alejandro Olano Garcia y Ernesto Rey Cantor. México: Gumesindo Garcia Morelos, Raymundo Gil Rendón, Manlio F. Casarin

83 Ley de Amparo: comentada, anotada y concordada con las normas provinciales, Buenos Aires: Astrea, 1979, p. 64.

84 Cfr., entre otros, "El derecho procesal constitucional y su configuración juridica (aproximación al tema)", en Revista Iberoamericana de Derecho Procesal Constitucional, núm. 2, op. cit; asi como su libro Derecho procesal constitucional, Bogotá, Temis, 2001, passim.

85 Cfr. el tomo I de su obra Derecho procesal constitucional. Recurso extraordinario, op. cit., pp. 3-6. 
y César Astudillo (México). Nicaragua: Iván Escobar Fornos. Panamá: Boris Barrios, Rigoberto González Montenegro y Sebastián Rodriguez Robles; y Peru: Samuel B. Abad, Edgar Carpio, Susana Castañeda, Luis Castillo Córdova, Francisco J. Eguiguren, Eloy Espinosa-Saldaña Barrera, Gerardo Eto Cruz, César Landa, José Palomino Manchego, Aníbal Quiroga León, Elvito A. Rodríguez Domínguez y Luís R. Sáenz Dávalos. Sólo por mencionar los que tienen obra escrita, enseñan la disciplina y que decididamente han contribuido significativamente a su consolidación.

En pleno siglo XXI el derecho procesal constitucional avanza hacia su aceptación plena dentro del concierto de las disciplinas juridicas, si bien todavía se requiere seguir configurando su contenido cientifico. 
